\title{
PENSAMIENTO EDUCATIVO DE ANTENOR ORREGO
}

\author{
Dr. Elmer Robles Ortiz ${ }^{1}$ \\ Universidad Privada Antenor Orrego Trujillo- Perú \\ Grupo de Investigación HISULA \\ ero_2502@hotmail.com
}

Recepción: 30/05/2008

Evaluación: 15/09/2009

Aceptación: 17/09/2009

Artículo de Reflexión

\section{RESUMEN}

Este artículo ensaya una reflexión del pensamiento de Orrego sobre educación, y se refiere a su definición y fines, contenidos y agentes educativos, estrategias del proceso de enseñanza-aprendizaje, educación universitaria, así como a la integración latinoamericana educativa y cultural. Precisamente, el presente trabajo busca reflexionar en torno a los aportes de Orrego en materia educativa, analiza y alcanza una interpretación de sus principales ideas, ubicándolas en el contexto histórico en el que fueron expuestas, y se las proyecta a nuestros días.

Se utiliza una metodología que aborda el pensamiento del autor estudiándolo en la perspectiva de la historia crítica del hecho educativo, y cuyo análisis hace posible encontrar una mirada prospectiva de su pensamiento en este campo. Las fuentes primarias y específicas de nuestro estudio son escasas, pero la producción bibliográfica referida a Orrego está en crecimiento, hecho notorio a partir de la publicación de sus Obras completas que incluyen una dispersión temática sobre educación, sobre todo las tomadas de periódicos y revistas.

Nuestro personaje conceptuó a la educación como herramienta para formar al hombre culto y al ciudadano, para terminar con la tiranía de la ignorancia, para formar la conciencia de nuestra realidad, y de la imperiosa necesidad de transformarla. Ubicó

\footnotetext{
1 Doctor en Ciencias de la Educación, Profesor de la Universidad Privada Antenor Orrego (UPAO), Trujillo, Perú. Profesor de la Escuela de Postgrado de la Universidad Nacional de Trujillo, Trujillo, Perú, Mencione Honorífica como Profesor Emérito de la Universidad Nacional de Trujillo en el año 2007. Actualmente es miembro del grupo de investigación Historia y Prospectiva de la Universidad Latinoamericana HISULA.
} 
al educando en el centro del quehacer pedagógico, para cuya formación se deberían considerar contenidos actualizados, al ritmo del vertiginoso desarrollo científico, poner en práctica métodos dinámicos y contar con docentes de elevada formación.

El artículo concluye que la americanización de América, el logro de su conciencia por sí misma, obra del nuevo hombre del continente que surge en medio del crisol de razas y culturas, con su mente fijada aquí, no en espacios foráneos. Sus ideas educacionales están enlazadas con su teoría del pueblo-continente o del integracionismo latinoamericano. Para lograr la unidad de la patria grande, definir la identidad regional, hacer frente al colonialismo mental y la copia simiesca del pensamiento ajeno a lo peruano y latinoamericano, la educación debe jugar rol central. La integración en la que están empeñados nuestros pueblos lleva ínsita la formación de la conciencia de tan magna aspiración. De allí su expresión: integración mediante el intelecto, cuyo cultivo es obra de la educación.

Palabras clave: Pensamiento Orreguiano, Educación, Formación Universitaria, Profesor, Maestro, Agentes Educativos, Realidad Social, Integración latinoamericana.

\title{
ANTENOR ORREGO'S EDUCATIONAL THOUGHT
}

\author{
Dr. Elmer Robles Ortiz \\ Universidad Privada Antenor Orrego Trujillo- Perú \\ Grupo de Investigación HISULA \\ ero_2502@hotmail.com
}

\begin{abstract}
Peruvian thinker Antenor Orrego Espinoza's work (1892-1960) is beyond dogmas and mental colonialism. With a new vision, he analyzes the historical process of Peru and Latin America in order to both address social problems and seek alternative solutions. Education is among these problems and alternatives, and is linked to its philosophical, sociological, political, and aesthetic ideas. He conceived education as a tool to train cultured people and citizens, end the tyranny of ignorance, and build awareness of our reality and the pressing need to transform it. From his thought, an education emerges completely centered on humankind: an education that reveals students' potentials and guides and ennobles them into the human development process towards the fullness of the human being; an education imbued with creativity and which drives social change. He believes that, since nature and society are never static, education must be either consequently. Therefore, the school should prepare students' brains to respond creatively to the evolving problems of their environment and the world. Thus, education will be like life itself: dynamic, ever-flowing, and a continuous revelation. And it must advocate
\end{abstract}


for Latin America integration. He conceives an integrated, dynamic, and flexible university; open to all currents of thought, creator and disseminator of culture, full of authenticity - that must respond to the reality in which it is settled.

This article tries to make reflection about Orrego's educational thought and concerns: its definition and purpose, content and education agents, strategies of teachinglearning process, university education, and the educational and cultural integration of Latin America.

Key words: Orreguiano Thought, Education, University training, Teacher, Professor, Education Agents, Social Reality, Latin American integration.

\section{INTRODUCCIÓN}

Desde una perspectiva intelectual original, Antenor Orrego Espinoza realiza su labor en el campo de las ideas filosóficas, sociológicas, políticas, estéticas y educacionales. Al reflexionar sobre el origen y destino de nuestros pueblos, formuló la teoría del pueblocontinente, trasfondo filosófico del integracionismo latinoamericano, cuya concreción requiere el aporte del campo educativo. Analiza la enajenación de América Latina desde los tiempos de la invasión y conquista. Y sostiene que ya no debe imitar servilmente a Europa, sino afirmar su identidad y su propia actitud original que no es una vuelta al pasado sepulcral, sino una revelación o alumbramiento hacia el futuro.

Aunque Orrego nació en 1892 en la hacienda Montán,

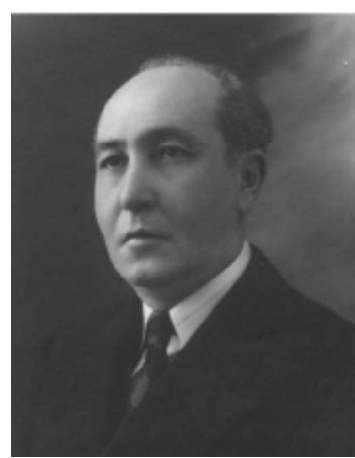

Dr. Antenor Orrego distrito de Lajas, provincia de Chota, departamento de Cajamarca, la ciudad de Trujillo fue su ciudad adoptiva en cuya universidad cursó sus estudios superiores. Fue mentor e integrante del histórico Grupo Norte surgido hacia 1915, en el cual figuraron, entre otros, los poetas César Vallejo y Alcides Spelucín, el ideólogo Víctor Raúl Haya de la Torre, el pintor Macedonio de la Torre y el músico Carlos Valderrama. Todos los integrantes de aquel grupo hicieron del interaprendizaje, de las lecturas colectivas, de los debates informales y de las excursiones, medios de educación no solo complementarios sino hasta superiores al de sus clases oficiales. Allí están sus libros, artículos, opúsculos, pinturas, partituras.

Publicó Notas marginales (1922), El monólogo eterno (1929) y Pueblo-Continente. Ensayos para una interpretación de la América Latina (1939). Fallecido en Lima el año de 1960, dejó inéditas la mayor parte de sus obras, editadas póstumamente, tales como: Discriminaciones (1965), Hacia un humanismo americano (1966), Mi encuentro con César Vallejo (1989). En 1995 aparecieron sus Obras completas en cinco tomos. 
Orrego fue docente de educación secundaria y universitaria, rector de la Universidad Nacional de Trujillo donde dejo huella perdurable. Pero sobre todo fue un maestro sin aulas que, mediante el diálogo informal, atendía cordialmente a jóvenes estudiantes, trabajadores e intelectuales cuyo consejo requerían sobre diversidad de temas.

Los escasos estudios sobre este personaje son principalmente de naturaleza literaria, filosófica, periodística y política; faceta dedicada a la de educación es la menos tocada, sin embargo, todos coinciden en otorgarle la categoría de maestro. Siempre pensó en la juventud. Desde su cargo rectoral consiguió el envío de estudiantes becarios a perfeccionarse en el exterior, que al finalizar su formación se incorporarían a la docencia o al ejercicio de sus profesiones. Muchos años después de esa función oficial, en el ocaso de su vida, solo dos veces viajó al exterior, a Argentina y a México. Y en ambas ocasiones sus actividades centrales fueron de carácter educativo y cultural.

\section{Definición y fines de la Educación}

Sin lugar a dudas, en su condición de humanista y educador, la formación del hombre ocupa lugar predilecto en el pensamiento de Antenor Orrego. En su concepto, el hombre vale por sus más fuertes impulsos, por sus más fuertes pasiones, no por las que se tornan negativas sino por las que ennoblecen. Por eso piensa que: "El problema de la educación no es suprimir las pasiones que son el impulso creador del hombre. El problema consiste en enseñar la superación de las pasiones hasta la máxima nobleza y en servirse de ellas como instrumento del espíritu". "El hombre sin pasiones es un exhombre, un ex-ser." ${ }^{3}$ Estuvo, por lo tanto, en contra del concepto común sobre la erradicación de las pasiones, lo cual conllevaría la castración moral del hombre. Alude, desde luego, a las pasiones que conducen hacia los valores, no a las que traicionan el destino del hombre tornándose monstruosa negación.

Para él, la educación no implica modelar el alma del alumno, por cuanto éste tiene demasiado porvenir como para que el pasado -representado por sus padres y profesorespretenda formarlo a su arbitrio. Son suyas estas palabras: "La educación no es inculcar y modelar; la educación es revelar, conducir y ennoblecer. El alma humana es demasiado sagrada para que nadie tenga la pretensión de modelarla a su capricho." ${ }^{4} \mathrm{Y}$ por ello pide mayor reverencia ante el educando, centro de atención del quehacer pedagógico.

Con tales ideas, publicadas el año de 1929 en su obra El monólogo eterno, Orrego se adelanta a las corrientes psicopedagógicas que sustentaron, mucho tiempo después, Vygotsky, Piaget, Ausubel y Rogers, entre otros, hoy en boga. Lo que él sostuvo hace 80 años, ahora impregna el quehacer educativo. Efectivamente, Orrego piensa que el profesor no debe formar al alumno a su antojo, a su estilo, a su gusto personal, no debe imponer un contenido educativo, sino ayudarlo a revelar su personalidad, a descubrir

3 ORREGO, Antenor. (1977): El monólogo eterno, $3^{\circ}$. Ed, Trujillo, Empresa Editora La

Razón, p. 17.

4 Ibídem, p. 18. 
sus potencialidades, orientarlo o conducirlo a construir su propio conocimiento, a ser protagonista del proceso cultural. Postula, pues, una educación para perfeccionar al hombre en el sentido de humanizarlo, de manifestar o expresar sus cualidades como creador de cultura y elevar al máximo las energías vitales de su ser. La idea de educación como revelación está relacionada con la de liberación. En efecto, este maestro sostiene que el conocimiento no es adquisición en el sentido estricto de posesión porque la riqueza espiritual no tiene carácter acumulativo sino liberador, esto es, de rompimiento de las cadenas que nos ligan al mundo físico y a la obra humana. Al conocimiento, entonces, lo descubrimos y revelamos y así queda al servicio del hombre, gracias a la educación.

Pero al mismo tiempo preconiza una educación para la transformación. Precisamente, coincidiendo con Karl Manheim, considera que la educación será eficaz solo si se orienta hacia el cambio. Y entiende como tal una educación para comprender el proceso evolutivo y el sentido de la época, captarlos con mente ágil y flexible, en todos sus ángulos: social, económico, político, científico, artístico, filosófico, y así lograr eficacia en el pensar y obrar. Sostiene que la vida es un permanente discurrir, un torrente de fluencia incontenible, por ello siempre es problemática; entonces para hacerle frente no valen los patrones hechos o las recetas fijas, sino una mentalidad capaz de conducir, mediante la creatividad, a soluciones acordes con cada nueva situación.

No siendo estáticas, pues, ni la naturaleza ni la sociedad, tampoco lo será la educación, de manera que la escuela habrá de preparar al cerebro del estudiante para reaccionar creativamente ante la cambiante problemática de su entorno y del mundo entero; consiguientemente, la educación será, como la vida misma, dinámica, siempre fluyente, un caminar constante, una revelación permanente y abierta a todas las posibilidades del espíritu, un proceso de creación y difusión de cultura, una vivencia cotidiana de valores.

Como la educación se inscribe en la esfera de la cultura y ambas se interrelacionan permanentemente, hacer labor de cultura, en el pensamiento de nuestro personaje, es hacer obra constructiva, educadora, imperecedera; es una acción que, en medio de hondas y lacerantes desgarraduras, decanta el espíritu, y con la cual el hombre deja su huella privativa en el curso de la historia. Precisamente, la cultura -para él- debe ser una cultura histórica, viva, encarnada en hombres concretos, no muerta, tampoco un simple escarceo de los académicos. Por ende, hay que saber vivir la cultura e incorporarla dentro de las fibras de nuestra vida. No debemos, tampoco, confundir cultura con ilustración académica; ésta implica memoria fría e inerte de la cultura pero no la cultura misma. Así, repetir un libro es muestra de ilustración; en cambio crear y vivificar el ambiente espiritual de una cátedra es muestra de cultura y de educación.

Y como educación y cultura son inseparables de la socialización, los diferentes escalones del sistema educativo tienen el ineludible compromiso de poner al alumno en relación con el entorno social mediato e inmediato. La educación debe advertir los grandes y graves problemas que afectan a la humanidad. Es un imperativo, obligación y responsabilidad de los jóvenes comprender con agudeza el sentido de su tiempo, la 
crisis en los órdenes moral, jurídico, económico, político y social, si no queremos precipitarnos en una catástrofe terrible y regresiva hacia la barbarie. El hombre debe poseer un cerebro tan fino y tan poderosamente organizado que le permita explicar y rebasar estos problemas. "Un cerebro preparado -anota- para el cumplimiento de esta función primordial no puede ser sino la obra de un adecuado sistema educativo que sea eficaz para capacitar a nuestra juventud en el desempeño de su misión histórica". ${ }^{5}$ Los estudiantes y las escuelas que fijan su atención únicamente en los contenidos de las asignaturas, desconectados del inmenso palpitar de la humanidad, tienen una visión estrecha, reducida, están inmersos en un proceso educativo parcial, incompleto; les falta orientar su mirada hacia todos los ángulos de la problemática del país, del continente y del mundo, sin esperar necesariamente una compensación mediante el proceso evaluativo oficial.

Consecuentemente, los currículos de todos los niveles educativos deberán tener en cuenta esta realidad. Las experiencias del proceso de enseñanza-aprendizaje no deben ser únicamente teóricas; su relación con la realidad, con las vivencias de los alumnos, con el contexto social donde se realiza es ineludible. Dice Orrego al respecto:

La educación puramente teórica arranca al hombre de su contacto con la realidad que lo circunda haciéndole vivir en un mundo imaginario o idealizado, que más que un campo de lucha es una evasión hacia la esfera de la ilusión y del ensueño. El hombre contemporáneo debe aprender a reaccionar original y vitalmente ante el ámbito de vida que le rodea. La vida es siempre problemática porque es siempre una afluencia y un cambio continuo, en que no valen los patrones hechos, ni los lugares comunes, ni las recetas fijas que, en vez de arribar a una solución, escamotean la dificultad por ignorancia o por miedo. ${ }^{6}$

Sus libros, especialmente las páginas en las cuales trata sobre educación, contienen un llamado a la originalidad y al cambio, a la formación de un nuevo hombre en América. Efectivamente, dice que la crisis del mundo reclama "el nacimiento de un nuevo tipo de hombre, nuevo desde su base telúrica y biológica, hasta a función de su inteligencia, de su actitud moral y de su espíritu." Entonces, la educación, no cabe duda, será el proceso ineluctable para lograr el desarrollo intelectual, moral y espiritual de ese hombre. Como América no ha expresado su aporte original ante el mundo en un todo tramado y contexturado, es decir, no ha tenido un estilo, modalidad vital o sentido con que se organiza y conforma sus factores biológicos, psíquicos, telúricos e históricos, la educación deberá buscar que el hombre nuevo sea capaz de expresarse en un estilo propio, inseparable de la formación de una conciencia histórica continental y de la fijación del destino de América mediante esa conciencia. Piensa que el oriente y el

\footnotetext{
5 Memoria del Sr. Rector Doctor don Antenor Orrego, al iniciarse el año académico de 1948. Universidad Nacional de Trujillo. 1948, p. 5.

6 Ibídem, p. 5

7 ORREGO, Antenor. (1957): Pueblo-Continente, ensayos para una interpretación de la América Latina. $2^{\mathrm{a}}$ ed, Buenos Aires, p. 69.
} 
occidente ya han cumplido sus destinos; el de aquél: "el dominio del mundo interno por el hombre, el dominio por sí mismo", el de éste: "el desarrollo de la inteligencia racional y el dominio del mundo externo". Entonces, cumplida ya la articulación de los mensajes de Asia y Europa, le ha llegado el turno a nuestro continente. "El destino de América -escribe- es resolver, en una superior unidad humana, la cuita angustiosa, la encrucijada trágica en que ha desembocado el mundo contemporáneo, y ser ella misma una continuidad y la continuidad del mundo."

Así como antes, la pendulación espiritual y cultural del mundo estuvo en Asia y después en Europa, ella pasará a América donde se producirá el parto cósmico de una cultura integral. América ha comenzado, según el pensamiento orreguiano, a expresarse y revelarse ante el mundo, y adquirirá coherencia y sentido histórico gracias a su conciencia, a su educación.

Como el niño que hace de su padre un modelo de referencia para sus actos, América ha desenvuelto su vida en forma extravertida, guiada por la resonancia o reflejo de Europa, siguiendo grotescamente estilos extraños. Ella ha sido como el eco de una voz lejana, la gesticulación vacía y cadavérica de la palabra viva de otros. Pero una cultura no llega a ser ella misma, si no penetra con agudeza en el hondón de sus raíces vitales. Mientras no alcance la intimidad abismática e inalienable de su ser, un pueblo no es órgano de expresión histórico. Esa intimidad es el estilo peculiar, el ritmo inconfundible de su existencia que imprime sello característico a la expresión de su cultura.

Para penetrar al secreto de su intimidad, los pueblos como los hombres individualmente tienen que dejar la infancia, durante la cual copian la intimidad de otros. Y solo después de una larga experiencia logran descubrirse y conocerse a sí mismos, llegan a ser ellos mismos, hecho ontológicamente consustancial a su propia existencia. Orrego utiliza la frase griega conócete a ti mismo para significar este proceso por el cual hombres y pueblos arriban a la comprensión del secreto de su intimidad, proceso ignorado por América durante largos siglos, y a cuyo fin asiste ya. Entonces, aquí ocurrirá lo que él denomina americanización de América, el hecho de conocerse a sí misma, discernirse a sí misma, llegar al fondo de su ser y, desde allí, expresar el mensaje de su propia alma.

Ahora bien, los hombres y los pueblos no podrán abismarse en la raigambre íntima de su ser, ni conocerse a sí mismos, distinguiendo la ficción de la realidad, para expresar su propia cultura, si no han sido educados formal e informalmente, proceso del cual son responsables los profesores y todos los agentes potenciales de educación, individuales e institucionales. Entonces, se requiere una educación para la americanización de América. Asimismo, postula una educación para el ejercicio de la democracia; una educación cívico-política para evitar que el pueblo sea arrastrado por caudillos ignaros e improvisados. Y una educación que recoja el veloz desarrollo científico y tecnológico.

\footnotetext{
8 Ibídem, pp. $67-68$.
} 


\section{Contenidos Educativos}

Con excepción de los contenidos del colegio universitario -registrados más adelante- no alcanza en forma expresa, sino indirectamente, algunos contenidos sin especificar el nivel educativo correspondiente. De modo general, tales contenidos corresponden a ciencia, filosofía, historia, economía, literatura, política, arte y religión, que los concibe formando un corpus, un complejo orgánico en función vital, pero que nuestro cerebro los divide en disciplinas. Orrego se refirió en diversas ocasiones a la revolución científica, particularmente a la era nuclear que, inseparable de la educación, tiene repercusiones en diferentes actividades humanas. Valora la ciencia, sin embargo piensa que bajo la racionalidad de la cultura occidental ha sido un error someter a consideración de la ciencia toda la obra del hombre e interrogar a la ciencia sobre lo que no se debe ni puede interrogarla. Por ejemplo, si la ciencia es interrogada acerca de un poema, ella contestará respecto a la realidad física del poema, pero jamás hallará el sentido y la esencia de ese poema. La ciencia opera sobre lo contingente, no puede agotar la realidad total, por ello también necesitamos acudir a otras esferas de la cultura, particularmente al arte.

Ciencia y arte, dice, son formas e instrumentos por los cuales la vida humana puede lograr su expresión plena. Ambos se complementan en la formación integral del hombre. Un mundo entregado a la pura ciencia sería deshumanizado, se movería dentro de generalizaciones escuetas y frías. De idéntica forma, un mundo abandonado al puro arte, no iría más allá de las improvisaciones intuitivas y quedaría a merced de las implacables fuerzas naturales. Si bien es importante el producto científico, no pueden omitirse el entusiasmo y las disposiciones del espíritu suscitadas por el resultado tangible de la creación estética. Para percibir el mundo, el hombre no acude solamente a su experiencia científica, sino también a su experiencia artística. El desarrollo de la capacidad de pensar con lucidez es tan necesario como el desarrollo de la imaginación, base de la invención científica y de la producción artística. La educación buscará, pues, el punto de concordancia y equilibrio de las matemáticas, física, química, anatomía y demás materias científicas con la pintura, la escultura, la música, la poesía y demás expresiones del arte.

Los contenidos educativos, en el pensamiento de Orrego, deben permitir a los estudiantes buscar en las aulas vida espiritual intensa; dilatar, ennoblecer y enriquecer su conciencia; conocer y comprender el sentido de su época; encauzar su curiosidad y su urgencia vital; vivir dando ejemplo. Los contenidos no deben fosilizar el cerebro de los jóvenes con erudición yerta; tampoco llenarlo con datos divorciados de la realidad, ni con frases rimbombantes sobre hechos nunca vividos. Enfatizó en aspectos valorativos, especialmente de carácter ético y estético.

\section{Agentes de la Educación}

En lugar de textos europeos que, mal comprendidos y mal aplicados, desorientan y fatigan con palabras vacías nuestros cerebros, reclama maestros capaces de enseñar a conocer y amar nuestro país y el continente, que vivan junto a la juventud y el pueblo la 
infinita y heroica tarea de crear cultura, de forjar un continente integrado por el intelecto, maestros brotados de las entrañas palpitantes de nuestra recóndita realidad. Y que por encima de los vaivenes políticos, sean intangibles porque son el factor decisivo en la educación. El pueblo debe respetar a sus maestros, que es una forma de respetarse a sí mismo, sino lo hace será un pueblo ausente de toda personalidad vigorosa.

Si bien los vocablos profesor y maestro son sinónimos, en el pensamiento orreguiano denotan diferencias indudables. En verdad, el profesor ejerce su labor en razón de un título profesional, a veces sin una verdadera vocación por la carrera; el maestro es tal por la trascendencia de su mensaje, no por el aval de un diploma. El profesor puede recitar en clase el contenido de un libro y creer que cumplió su tarea; por el contrario, el maestro debe crear y vivificar la relación espiritual entablada con sus discípulos, sea en el aula o en otro ambiente.

No siempre el profesor es maestro. Orrego los diferenció nítidamente en sus escritos. El profesor, dice, enseña para que el alumno pueda repetir la lección, en cambio el maestro enseña para que el discípulo pueda construir su vida. El primero imparte generalidades abstractas, encasilla al alumno como una pieza estándar y seriada dentro de un esquema rígido. El segundo desciende a la intimidad del alma para que aflore la riqueza interior del educando y lo convierta en compañero de su pasión y de sus inquietudes. Mientas el profesor fija al estudiante en un oficio, el maestro lo libera hacia la vida plena. Con el profesor, la habilidad del educando puede llegar hasta la ilusión de esconder la verdad, pero con el maestro es preciso que el discípulo asuma toda su responsabilidad y descienda a la profundidad de su propia vida, aunque fuese tenebrosa y lacerante. Lo que da el profesor está fuera del alumno y lo fija con un simple gesto; por el contrario, lo que ofrece el maestro está siempre dentro del educando y le da energía para seguir adelante. El trabajo del profesor es como el agua que discurre sobre la superficie sin penetrar a la raíz de la planta, y no se sume en las entrañas de la tierra. Por su parte, la obra del maestro es la linfa creadora que bate el limo, lo empapa y fecunda para producir una floración maravillosa. El profesor apunta a la memoria y sus palabras se esfuman sin dejar huella perdurable, resbalan sin lograr infiltración alguna. El maestro se dirige al espíritu, pozo de creación y de sabiduría, y su mensaje trasciende e impregna la vida del discípulo.

Pero también diferencia alumno de discípulo, según el tipo de relación pedagógica establecida en el aula. Si la relación es instrumental, es decir, exclusiva y fríamente centrada alrededor del contenido educativo, se hablará de alumno ya que éste -por indicación del profesor- sólo aprende el contenido de una clase y trata de rendir satisfactoriamente las pruebas del examen. En cambio si la relación es expresiva, esto es, llena de mensajes estimulantes y compenetrada de afectividad, se hablará de discípulo -que gracias a la orientación de su maestro- busca clarificar valores y guiarse por ellos, integrar ideas y hábitos positivos en una filosofía de vida. El correlato de la categoría profesor es alumno, el de maestro es discípulo. Y de modo específico en lo atinente a la universidad, como ésta no ha sido ajena a desempeñar el papel de diablo predicador, Orrego reclama a profesores y alumnos consecuencia con lo que enseñan, a unos, y con lo que aprenden, a los otros. 
Pide a ambos protagonistas de la educación realizar su tarea a mayor profundidad y a estrechar su relación pedagógica. Les dice: "Catedrático que se contenta con ser simplemente un profesor y alumno que solamente aspira a alcanzar el resultado satisfactorio de sus pruebas finales, no son precisamente los factores que crean el vibrante espíritu institucional de una universidad. El profesor debe ser a la vez maestro y el alumno debe alcanzar la categoría de discípulo." A los docentes les exige demostrar el espíritu de su elevado magisterio, y a los alumnos estudiar por vocación; a ambos estamentos, dejar el concepto utilitario como único fin, y armonizar sus intereses materiales e ideales.

Su paradigma de maestro es el que está contagiado de americanismo, el que tiene la mente fija aquí, en esta tierra, no el que plagia todo de Europa. Por eso celebra que el movimiento de reforma universitaria (de los años veinte del siglo pasado) haya ejercido influencia positiva sobre los docentes: "Los maestros de América-los mejores- eran solamente buenos maestros europeizados, pero América necesitaba más, necesitaba buenos maestros americanos. Y asistimos, entonces, a un maravilloso autodidactismo de la juventud sobre los maestros. La juventud comienza a formar maestros, comienza a americanizarlos. El maestro se ha convertido en discípulo porque necesita aprender y desarrollar su sentido histórico, su sentido americano." 10 Y los estudiantes que van a la universidad no solo para adquirir un título, sino por encima de todo para ser hombres cultos, se vieron obligados a desaprender lo aprendido, por no servirle para pensar ni ser mejores, e iniciaron el camino de su propia formación.

Pero hay otro rasgo importantísimo en su paradigma de maestro. Ya en su madurez, recordando sus años de colegial, destacó el aspecto afectivo, profundamente humano, de la relación educativa. Entonces escribió en homenaje a uno de sus maestros estas palabras: "Un maestro de verdad salva siempre el sentido y la dignidad de una vida. No son enseñazas frías que nos da sino que nos entrega, junto con ellas, su propio corazón, nos fecunda con su ternura y nos redime para siempre de todo horrible mal." ${ }^{11}$

Hace una comparación del cerebro con las instituciones educativas. No obstante las limitaciones de los centros de estudios, los defiende, y critica la agresión infringida contra ellos por los gobiernos tiránicos que practican una amputación de la inteligencia, como sucede cuando clausuran violentamente universidades. El cerebro, dice, centraliza todas las funciones biológicas, las armoniza para producir vida normal traducida en salud, energía, fuerza, capacidad para actuar. Así también, las instituciones educativas, agentes que cultivan el cerebro, centralizan, coordinan y organizan las diferentes actividades del Estado, la vida de la nación.

\footnotetext{
9 Memoria del Sr. Dr. don Antenor Orrego, Rector de la Universidad Nacional de Trujillo, leída el día de la apertura del presente año académico, Trujillo, Perú, 1947, p. 9.

10 ORREGO, Antenor. (1928): “El gran destino de América ¿Qué es América?”, en Amauta, Lima, Año III, No 12, febrero de 1928, p. 14.

${ }^{11}$ ORREGO, Antenor. (1998): Mi encuentro con César Vallejo, Bogotá, Tercer Mundo Editores, p. 49.
} 


\section{Estrategias del proceso de Enseñanza-Aprendizaje}

La educación como revelación y para el cambio implica nuevas bases teóricas. La pedagogía que sólo tenía en cuenta al profesor, no al alumno, queda descartada. Por eso Orrego acude a los grandes teóricos paidocentristas cuyas ideas realizan un viraje radical e imprimen al proceso de enseñanza-aprendizaje un nuevo sentido: "el viraje del saber y del maestro hacia el estudiante. El maestro no debe preocuparse tan sólo de lo que enseña, es decir el conjunto de conocimientos que posee, sino también, y muy principalmente, debe preocuparse de cómo enseña, de qué es lo que debe enseñar y cuál va a ser la influencia y la repercusión de sus enseñanzas en el espíritu del alumno". ${ }^{2}$ Se nutre de los postulados de la escuela nueva, y no cae en los extremos ni del cognoscitivismo ni del metodologismo, buscó el equilibrio en la tarea docente.

Fustiga la docencia europeizada y le reclama actuar con realismo. Anota: "Los textos europeos mal aplicados y mal comprendidos no sirven sino para desorientarnos (...) y para fatigar con gárrulas palabras nuestros cerebros y nuestra vida". ${ }^{13}$ Piensa que los alumnos deben someter los libros a su espíritu y no su espíritu a los libros. Por ello exige docentes de elevada capacidad creativa y una enseñanza orientada a conocer y amar el Perú y América; una enseñanza para internalizar valores, normas de vida, comportamientos durables y no circunscrita a simples actividades pasajeras como las consignadas en los programas de estudio que no pasan de la epidermis del espíritu. E invoca a la juventud -guiada por sus maestros- a buscar ruta propia, descubrir, comprender y transformar nuestra realidad, cumpliendo así su misión histórica. $\mathrm{Su}$ libro Pueblo-Continente está expresamente dedicado a las nuevas generaciones del Perú y de América Latina que sienten el acendrado, el vivo apremio de encontrar su propia alma. Allí les pide, dejar de lado el deslumbramiento provocado por Europa, orientar sus fuerzas creadoras a descubrir la realidad de nuestra América, desgarrando la crisálida que aún la cubre para hacerla resurgir a un nuevo amanecer de la historia.

Textualmente les dice: "Sois una promoción histórica privilegiada porque el desencanto de lo ajeno y de lo extraño ha traído la fe y la esperanza en vosotros. Sé que esto sólo se alcanza a través de profundas y dolorosas desgarraduras; pero, es preciso que cada hombre y cada pueblo asuma la majestuosa responsabilidad de su lágrima y de su dolor, porque la mariposa no surge hacia la luz sino después de romper y desmenuzar en cendales el sudario que la envolvía". ${ }^{14}$ Invita a la juventud a emprender la búsqueda de nuestra América, alejándose en este viaje intelectual del mágico hechizo de la imaginación exótica, para encontrar su propia y auténtica ruta, no obstante el proceso lacerante que habrá de seguir.

Poniendo énfasis en esta problemática, analiza el estrago mental producido en la juventud latinoamericana por el plagio simiesco y el transplante irracional de ideologías

\footnotetext{
12 Memoria anteriormente citada, pp. 9-10.

13 ORREGO, Antenor. (1928): “Cultura universitaria y cultura popular”, en Amauta. Lima. Año III, $\mathrm{N}^{\circ} 16$, julio de 1928, p.36.

14 ORREGO, Pueblo-Continente. Op. Cit, p.10.
} 
surgidas como expresión de hombres que viven otras realidades. Sobre este asunto escribe: "Extensos sectores de la juventud están perdiendo toda curiosidad y autonomía mental, toda libertad interior de pensamiento, porque bajo el agobio de un dogmatismo de nuevo cuño, el cerebro se paraliza y es imposible pensar por cuenta propia" ${ }^{15} \mathrm{Le}$ preocupa, pues, a Orrego que el cerebro del joven produzca tan solamente un juego de palabras y frases vacías repetidas de textos ajenos, distantes de la intransferible realidad del Perú y Latinoamérica. Lo cual no significa que él sea xenófobo o abrace un nacionalismo agresivo. El hecho de exigir sentido creativo y buscar nuestra identidad cultural no se opone a la valoración del pensamiento foráneo, mas no lo conceptúa como cartabón o grillete.

"Política y culturalmente dice no seremos libres, sino simplemente libertos y manumitidos mientras sintamos la añoranza de las palabras y de los ademanes extraños. Si sentimos el pensamiento europeo como yugo y no como sustancia nutricia y alumbradora, ¿cómo habremos de alcanzar nuestra autonomía, nuestra soberanía y mayoría espirituales?" 16 Es reiterativo al pedir a la juventud pensamiento autónomo, no esperar que sus juicios le vengan ya hechos por otros. En un mundo cambiante a cada instante no hay lugar para la negligencia ni para el ocio de tiempos pasados. Y en esa dirección habrá de realizarse la función docente.

"La sabiduría en su concepto- no es tanto la posesión del conocimiento sino el esfuerzo y el camino al conocimiento." ${ }^{17}$ En tal virtud, no hay sabiduría infusa, sino lograda con sufrimiento, conquistada y vencida después de esmerado trabajo; la enseñanza basada en el viejo precepto del magister dixit, puramente teórica, ha fracasado en la vida moderna. Por eso anota: "El maestro debe enseñar en tal forma que el alumno tenga la impresión de que aquello que aprende lo extrae de su propio trabajo y de su propio afán, porque ésta es la única enseñanza que se prende profundamente en el espíritu del joven y lo cultiva fecundando el esfuerzo del estudiante." 18 Vale decir, preconiza una docencia que le permita al alumno aprender contenidos significativos, que incorpora en su estructura cognitiva, impregna su intelecto y le permite seguir perfeccionándose aún cuando haya egresado de las aulas.

Observa y comprende el desarrollo del conocimiento en tal magnitud, velocidad y poderío que hace imposible su aprendizaje total en la ciencia, el arte, la filosofía y la historia. Una tarea de ese tipo sería absurda. Entonces, el docente debe tener la cualidad de sintetizar los tópicos fundamentales de la disciplina a su cargo y poner en manos del alumno las herramientas metodológicas para que se agencie del conocimiento. Felizmente, ahora, disponemos de un conjunto extraordinario de medios intelectuales y materiales para el autoaprendizaje. Y se impone la necesidad de usar contenidos instrumentales para ir en pos de la riqueza cognoscitiva. La realidad de nuestro tiempo confirma las previsiones orreguianas. El conocimiento se duplica cada cuatro años, y

15 Ibídem, p. 17.

16 Ibídem, p. 18.

17 El monólogo eterno. Op. Cit, p. 74.

${ }_{18}$ Memoria. 947. Op. Cit, p.11. 
en parte queda obsoleto. Y se abre paso la sociedad del conocimiento o de la información columbrada por él con nitidez.

Orrego propugna un proceso de enseñanza-aprendizaje a través de métodos dinámicos, para lo cual sitúa en el primer plano didáctico a la investigación y al seminario. Critica duramente la enseñanza unidireccional, rígida, yerta, memorista, encasillada en tópicos resueltos de antemano, mediante la cual no se obtienen resultados vitales, sustantivos -hoy decimos significativos- que el profesor y el alumno deberían perseguir en conjunto. Dirige su atención y entusiasmo al método activo del seminario (especialmente en todas las carreras universitarias) visto como un organismo que diariamente acrecienta sus experiencias, y por acumular información en sus archivos es más eficaz que una biblioteca: pueden llegar a ser tan valiosos dichos archivos que profesores y alumnos encontrarían allí datos, sugestiones, normas, actos y orientaciones necesarios para plantear un tema, desarrollarlo y alcanzar las soluciones de un problema del contenido educativo. De esta manera, con un método dinámico: "El maestro propiamente sólo debe orientar y dirigir el trabajo de los alumnos dejándolos en plena libertad de iniciativa para el desarrollo de los temas. Cada clase, cotidianamente, debe constituir un verdadero problema que se plantea ante al maestro y los alumnos y que ambos deben resolverlo cada día". ${ }^{19}$ Esta dinámica metodológica permite hacer de cada disciplina no solo emisión magistral del contenido, sino fundamentalmente un intercambio fluido de pensamiento con el cual tanto maestros como alumnos aprenden al mismo tiempo. El hecho de preguntar ya entraña enseñanza y aprendizaje, y el hecho de responder también. El seminario está enlazado con la resolución de problemas.

Existe alguna semejanza de las ideas expuestas con las divulgadas en los últimos tiempos bajo el rótulo de constructivismo pedagógico. Sin embargo, los embriones del pensamiento de Orrego son anteriores a la difusión de dicha tendencia.

Durante su gestión rectoral en la Universidad Nacional de Trujillo, la biblioteca mereció especial atención, y la revista institucional alcanzó su mejor época. Asimismo impulsó enormemente el Museo de Zoología. Y pensó que los colegios también deberían contar con esos museos para el proceso de enseñanza-aprendizaje de carácter práctico, a los cuales la Universidad brindaría apoyo con su taller de taxidermia. En el campo de la botánica, inició la formación del herbario regional. Enriqueció con nuevas colecciones el Museo Arqueológico, y desde él promovió los estudios in situ de esa especialidad. Además dio vida a institutos y nuevas facultades. Y en su plan de ejecución de la ciudad universitaria se consignaron, entre otros, ambientes para jardín botánico, jardín zoológico, museos, gimnasio y estadio.

En el campo universitario, plenamente convencido de los aprietos por vencer en el afán de romper viejos esquemas, piensa que tras un trabajo dilatado de profesores y alumnos se creará un vibrante espíritu de renovación, un nuevo sentido del proceso de enseñanza-aprendizaje:

\footnotetext{
19 Ibídem, p. 11.
} 
Comprendo que la tarea es dificil y que no puede realizarse sino gracias a un esfuerzo prolongado de los que enseñan y de los que estudian; pero el profesor debe aspirar siempre a lograr la alta categoría de maestro y el alumno debe esforzarse también para alcanzar la no menos alta categoría de discípulo. Quiero decir que la enseñanza no debe quedarse en la superficie del programa y en la epidermis del espíritu, sino que debe calar mucho más hondo, hasta constituir verdaderas normas de vida y si se quiere, en casos excepcionales, debe alcanzar el apostolado y hasta la heroicidad. ${ }^{20}$

Orrego preconiza una educación para calar a profundidad en el espíritu de los alumnos hasta incorporar los contenidos de aprendizaje como verdaderas normas de vida. En el ámbito universitario conlleva una idea de transformación académica, una nueva universidad, con verdadero sentido docente, donde el profesor no se contente con el simple y estricto cumplimiento de sus programas, y el alumno solamente se preocupe por aprobar los exámenes, sino que ambos sean hacedores de cultura, constructores de conocimiento, forjadores de valores. En varias ocasiones toca este asunto, considerado como uno de los fundamentos de la nueva universidad que él postula, universidad dinámica, flexible e integral.

\section{Educación Universitaria}

Cuando el Senado de la República debatía el proyecto del Estatuto Universitario (1946), Orrego defiende, desde su curul parlamentaria, la idea de universidad conformada por profesores, alumnos y graduados, como ahora la entendemos. En aquella ocasión expresa:

El artículo primero declara que la universidad es la asociación de maestros, de alumnos y de graduados; es decir, la universidad en sus tres dimensiones integrales, como un todo o núcleo viviente que surge del presente y se proyecta como fluencia al porvenir. Este artículo rompe con el concepto antiguo de la universidad, que parecía querer reducirla al cuerpo profesoral de las aulas, como si los egresados no fueran parte sustancial de ella, como si no estuvieran bebiendo las enseñanzas de su fuente maternal y como si no estuvieran obligados a volver a su seno a enriquecerla con la cosecha de su pensamiento, de su experiencia y de su acción. ${ }^{21}$

Mucho antes, en 1923, en el fragor del movimiento de la reforma universitaria, ya había sostenido que por la falta de entendimiento entre profesores y alumnos respecto a quienes constituyen la universidad, no se podía esperar ninguna enseñanza viva, ninguna creación efectiva para la sociedad y con proyección hacia el porvenir. Por entonces, la separación entre ambos sectores llegaba hasta el rechazo mutuo que impedía

\footnotetext{
${ }^{20}$ Ibídem, p. 9.

21 ORREGO, Antenor. (1995): "Discurso en el Senado de la República. Debate sobre Reforma

Universitaria (1946)," en Obras completas, Lima, Editorial Pachacutec, t v, p. 191.
} 
todo nexo afectivo, base del proceso de enseñanza-aprendizaje fecundo leamos sus palabras: "El criterio de que la Universidad está constituida, únicamente, por el profesorado revela un concepto petrificado de la enseñanza. La Universidad no se ha hecho para mantener catedráticos, sino para 'enseñar alumnos'. Son estos, pues, la materia viva, la materia moldeable, el cuerpo y el alma necesarios. La enseñanza debe sujetarse a sus exigencias y necesidades espirituales y, por eso, son ellos, principalmente, los que deben fijar las condiciones de la docencia." ${ }^{22}$ Y obviamente, defiende el principio de participación de los alumnos en el gobierno de las universidades.

Al profesor lo considera elemento responsable de prestar el servicio al estudiante, que es la sustancia viva e indispensable y merece ser atendido en todo lo necesario para su formación. Postula la conveniencia de las cátedras paralelas y cátedras libres, para una mejor selección docente según la capacidad y no por imperio de las camarillas u oligarquías académicas.

Para Orrego no basta tener infraestructura, legislación y régimen académico impecables, lo importante es que la universidad se vincule y responda a la realidad natural y social circundante. "Por perfecta que sea una universidad extranjera no puede nunca adaptarse a las realidades palpitantes, genuinas y sustanciales del pueblo en que debe vivir. La Universidad Nueva debe surgir como un árbol frondoso que ha hincado vigorosamente sus raíces en el seno de su madre, porque la universidad solamente puede hacer su auténtico camino asimilando los jugos de la tierra que la nutre. ${ }^{.23} \mathrm{La}$ universidad en el Perú y Latinoamérica no puede seguir el tipo de las universidades de Europa o Estados Unidos porque nuestra realidad histórica, psicológica y social es diferente. Cada universidad es el producto temporal y telúrico de un pueblo. Debemos, entonces, crear una universidad que refleje nuestra problemática, que sea el instrumento de investigación y el órgano que dilucide la creación de nuestra cultura. El nuevo tipo de universidad propuesto es llamada Universidad Indoamericana.

Es decir, la universidad no puede transferirse o trasladarse de una realidad a otra completamente distinta; no se trata de una mercancía sometida al juego de la oferta y la demanda, sino de una institución creadora de cultura; cultura que nace y crece en una sociedad concreta, por tanto hay que vivirla dentro de nosotros en el proceso dramático, y aún trágico, del Perú y de América; cultura que surge de la vida de los conglomerados humanos en el curso de su propia e inconfundible historia y se proyecta con su mensaje hacia otros pueblos del mundo.

Entonces, Orrego formula la misión de la universidad en los siguientes términos:

La significación de este mensaje universal se clarificará y se hará plenamente consciente a través de la Universidad Nueva, que tiene la misión impostergable de recoger en su seno las experiencias, las intuiciones, las

\footnotetext{
22 Obras completas, t II, p. 224.

${ }^{23}$ Memoria.1947. Op. Cit, p. 7.
} 
esperanzas, la fe y el pensamiento de América. Esta misión de la Universidad Nueva debe realizarse a través de todas sus Facultades e Instituciones Docentes. Cada maestro debe esforzarse en imprimir esta orientación a sus enseñanzas, porque desde el Derecho, desde la Química, desde la Medicina, desde el Arte, desde la Filosofia, la universidad debe inquirir y definir con entera claridad qué es América como valor especifico y original en las artes, en la ciencia, en la economía, en la filosofia. ${ }^{24}$

Esta orientación de la universidad implica creatividad; abrir paso al pensamiento divergente; buscar lo auténtico sin omitir el aporte de otras culturas; combatir el colonialismo mental, la repetición simiesca e irreflexiva de textos y formulaciones del pensamiento que no se avienen con lo nuestro, con lo peruano y latinoamericano.

Según el pensamiento de Orrego, la universidad no puede quedar marginada de su contexto social, por el contrario, debe cumplir rol protagónico y vital en el mismo centro del quehacer colectivo, sin aislarse cual ostra parasitaria, lejos de las aspiraciones juveniles y del grito angustioso del pueblo al cual se debe. Él concibió la universidad como un organismo vivo cuyos procesos de crecimiento y estructuración son incesantes. Se propuso por ello: "Hacer de la antigua universidad estática un proceso dinámico de evolución que sepa incorporar, paso a paso, en superación constante, la vida total de la nación." ${ }^{25}$ Pero como es un visionario en temas sociales y educacionales, se proyecta al futuro y anuncia:

(...) la realización de un proyecto integral de Universidad Nueva en armonía con la concepción moderna de que ella debe ser un foco de iluminación intelectual y moral y una antena que recogiendo las palpitaciones del Universo y de la Vida, se proyecte profundamente hacia el pasado e infinitamente hacia el futuro. Sólo así podríamos hacerla responder a la realidad de una América Nueva, al ritmo de un mundo que está realizando una acelerada transformación técnica, social y económica. ${ }^{26}$

Puesto que la sociedad y la educación son cambiantes, la universidad también deberá serlo, es decir, la entendió como una institución activa, ágil, en transformación, un proceso en constante superación, que potencia las supremas energías intelectuales, capaz de incorporar al debate académico el diagnóstico y la solución de los grandes problemas del país; consiguientemente, sus miembros serán emprendedores, eficaces, resolutivos, ajenos a la abulia e inmovilidad.

Defiende una universidad en cuyas aulas se ofrezca cultura general y especializada, armónicamente equilibradas; se forme al hombre en todas sus dimensiones, integralmente, de modo que el profesional sepa desenvolverse con idoneidad en su

24 Ibídem, p. 8.

25 Ibídem, p. 4.

26 Memoria 1948. Op. Cit, p. 21. 
campo, pero, asimismo pueda discernir ante la síntesis del conocimiento global. Una universidad que forma expertos en la aplicación de una disciplina científica, pero al mismo tiempo, humanistas, académicos, que tengan el sentido general del mundo y de la historia, todos ellos hombres de amplia cultura y claros conceptos de los problemas sociales, morales, políticos y económicos de su época.

Una universidad que realiza enseñanza a través de la investigación científica; fuente de poderosa irradiación cultural y moral, hondamente enraizada en la historia, pero también con la mirada dirigida al inagotable porvenir; centro receptor del acontecer vital del contexto humano donde funciona y de la acelerada transformación científica, tecnológica, social y económica del mundo; que responda a la realidad peruana y latinoamericana, y prepare generaciones aptas para desempeñarse en la vida y laborar en favor del desarrollo. Una universidad que no esté de espaldas de su realidad, divorciada de su contexto social, sino asentada en tierra firme.

Así, estamos frente a una universidad dinámica, flexible e integral. En reemplazo de la antigua universidad estática, petrificada, profesionalizante y por ello unilateral, repetidora del pensamiento europeo, marginada del clamor popular, Orrego concibe y defiende una universidad dinámica, semejante a un organismo vivo, un laboratorio de renovación y creación espiritual; flexible ante un mundo cambiante por el proceso de la historia y de la ciencia, abierta a todas las energías del espíritu; integral, orientada hacia la formación plena de nuevos hombres; nacida y situada en la hondura de nuestra realidad; fuente creadora de cultura; pletórica de unionismo latinoamericanista; medio para la expresión del universalismo cultural que habrá de consumarse en el futuro; instrumento vital del desarrollo. Al hablar de universidad integral, hace la salvedad de la redundancia porque el significado originario de universidad, universitas, indica integración de elementos culturales de todos los espacios y tiempos.

Estas ideas datan de 1946. Cincuenta años más tarde, coincidirá con ellas la UNESCO y Carlos Tünnermann, al propugnar se tenga en mente, cuando se formulare la misión de los sistemas de educación superior, la nueva misión de "la universidad dinámica" o "proactiva". Esta noción de universidad dinámica auspiciada por la UNESCO supone como sostenía Orrego su adaptación creativa, por cada país, en el proceso de búsqueda de modelos y prácticas institucionales específicos en relación con el desarrollo, pero sin desconocer las influencias de un mundo rápidamente cambiante, y que se oriente, entre otras cosas, a convertir a cada institución académica en:

(...) un lugar de formación de alta calidad que capacite a los alumnos para actuar de manera eficiente y eficaz en una amplia gama de funciones $y$ actividades civicas y profesionales, incluyendo las más diversas, actuales y especializadas; una comunidad dedicada plenamente a la investigación, la creación y la difusión del conocimiento, al progreso de la ciencia, y que participe en el desarrollo de innovaciones e invenciones tecnológicas; (...) un lugar en el que se individualicen, discutan y aborden en espíritu de crítica bien informada problemas y soluciones locales, regionales, nacionales e internacionales importantes, $y$ en el que se fomente la participación activa 
de los ciudadanos en los deberes sobre el progreso social, cultura e intelectual; (...) una institución bien ubicada en el contexto mundial con todas las amenazas y las posibilidades inherentes, y adaptada al ritmo de la vida contemporánea, a las características distintivas de cada región y de cada país. ${ }^{27}$

Las universidades profesionalizantes tienden a mecanizar la función docente, olvidan que por encima de ello deben formar al hombre y al ciudadano capaces de comprender su entorno y crear la nacionalidad. Escribe el maestro:

Antes que formar académicos, necesitamos que se formen hombres, hombres de espíritu robusto que reaccionen contra la mezquina realidad circundante, que tengan un pensamiento, una ideología, una sensibilidad, ante los más perentorios y urgentes problemas nacionales y humanos. Todos estamos de acuerdo en que no tenemos nacionalidad, en que es menester crearla; $y$, sin embargo nuestros más altos institutos de enseñanza se empeñan en no forjar creadores de nacionalidad. ${ }^{28}$

La universidad, entonces, lejos de centrarse en la formación de profesionales y en el afán exclusivista de la especialización, debe partir de la formación del hombre culto. Considera a la cultura general y a la síntesis coordinada del conocimiento como una base sólida sobre la que debe asentarse la investigación científica y la escuela profesional. Por eso ve al colegio universitario como una fuente de cultura general, científica y humanística, el pórtico de la formación profesional y de la investigación, una suerte de ciclo básico o de estudios generales, nexo entre la educación secundaria y universitaria. Este organismo prepararía el cerebro del estudiante para convertirlo en herramienta eficaz de conocimiento, de estudio, de curiosidad y de investigación, proceso indispensable para formar después al especialista en una ciencia y al humanista. Su caracterización del profesional es muy clara: "El profesional no sólo debe ser un hombre que sepa mirar aguda y profundamente a través del ojo estrecho de una cerradura, sino también un hombre de mirada panorámica, que no se asuste frente al miraje total del horizonte y que sepa darse cuenta del conjunto del mundo, de la Historia, de la Filosofía y de la Ciencia como síntesis global del conocimiento humano." ${ }^{29}$

Por tanto, el colegio universitario debería encarar el problema de la cultura desde cuatro aspectos, anunciadores de contenidos generales de aprendizaje:

\footnotetext{
${ }^{27}$ UNESCO. (1995): Documento de política para el cambio y el desarrollo de la educación superior, París, Talleres de la UNESCO, p. 53-54. Y TÜNNERMANN BERNHEIM, Carlos: "La educación superior en América Latina y el Caribe en su contexto económico, político y social", en Luis YARZÁBAL, Editor. (1997): Hacia una nueva educación superior, Actas de la Conferencia Regional Políticas y Estrategias para la Transformación de la Educación Superior en América Latina y el Caribe, realizada en La Habana, del 18 al 22 de noviembre de 1996. Caracas, CRESALC/UNESCO, pp. 163, 164-165.

${ }^{28}$ ORREGO, Antenor. Obras completas. Op. Cit, t I, p. 383.

${ }^{29}$ Memoria. 1947. Op. Cit, p. 6.
} 
$1^{\circ}$ el proceso histórico del hombre (historia);

$2^{\circ}$ la concepción de los fines de la vida humana (filosofía);

$3^{\circ}$ la imagen física del universo (física y química), y

$4^{\circ}$ los fundamentos de la vida orgánica (biología).

Pero el alumno, para llegar a ser hombre culto, no debería aprender tales contenidos a través de fórmulas matemáticas, técnicas de experimentación, hipótesis, tesis y teorías que son propios del investigador específico y de la escuela profesional correspondientesino lo que representan las disciplinas académicas como aporte, orientación, renovación, acrecentamiento de la totalidad del saber y del conocimiento contemporáneos.

Si la universidad estuviese centrada en la formación del profesional y descuidase la del hombre culto, produciría un desequilibrio; de ella podrían egresar profesionales distinguidos, investigadores admirables sin que sean, necesariamente, hombres cultos en el sentido pleno de la palabra. Aquellos profesionales -sostiene en su crítica aparecerían como criaturas débiles que marcharían por la vida agobiadas por su título, por su carrera y por su lucro, sin responsabilidad moral, que lo mismo les daría vivir con sus ideas, con la justicia, con la verdad, o sin ellas y hasta en contra de ellas. De esta manera, nada podríamos esperar y exigir de profesionales con tales características, que son la degradación de la actividad universitaria. Formar al hombre y al ciudadano antes que al profesional es, por ende, tarea primordial de la universidad. Ciertamente, las personas no siempre actúan en consecuencia con los principios que declaran. La aguda observación del maestro contenida en el fragmento siguiente exhibe una dolorosa realidad.

La universidad ha tenido una semi-cultura de gabinete y de pupitre pero no ha tenido ni tiene una verdadera cultura vital. La cultura hay que vivirla en principio y vivirla en acción. No se puede, pongamos por caso, explicar y defender en el aula las llamadas garantías individuales y atropellarlas y negarlas en la calle y en la vida cotidiana". "No vale la pena que en los exámenes se declame de corrido el amor a la libertad, al derecho y a la justicia y en la vida se les befe, o por lo menos, se muestre uno diferente a sus imperativos categóricos. "30

La cita precedente nos pone frente a situaciones de pasmosa vigencia no obstante remontarse al año de 1928, aplicables en diversos campos de nuestra vida política y universitaria. Concibe a la cátedra como un intercambio viviente, entusiasta y hasta apasionado entre docentes y alumnos, fluyente, abierto a la discusión libre, una comunidad y fraternidad de diálogo permanente, de afecto y conocimiento. Hacer cátedra, hacer universidad y hacer país implica fundamentalmente vivir la cultura, no sólo practicar la regurgitación de conceptos, hechos, datos, formulaciones filosóficas, leyes o teorías científicas. Por eso, considera que la gran empresa de los universitarios es, precisamente, vivir la cultura. Y rechaza el eruditismo vacío, carente de sustancia,

${ }^{30}$ ORREGO, Antenor. Obras completas. Op. Cit, p. 306.

Rhela. Vol. 13. Año 2009, pp. $101-127$ 
que no sirve para la mejora individual ni colectiva. Postula, por el contrario, el conocimiento de nuestra problemática. Necesitamos, escribe, "crear nuestro propio pensamiento, nuestra propia política, nuestra propia economía, nuestra propia estética, nuestra propia historia." ${ }^{31}$ Tal obra creativa exige esfuerzo investigador.

Sostiene que la universidad debe ser la depositaria y discernidora de la experiencia histórica, por ende, no puede vivir y quedar aislada en la periferia de los pueblos, sino ella debe vivir en la médula vital de su contexto social. Y como la universidad ha vivido los vaivenes de la vida política de la república, en un desplazamiento pendular de gobiernos de origen democrático y de gobiernos autoritarios, las juventudes impulsoras del movimiento reformista propagado a partir de 1918 y 1919 pensaron a lo largo y ancho de América Latina que la docencia en esta parte del mundo habría de caracterizarse por ser, primordialmente, docencia ciudadana, practicante de la pedagogía social. En un Estado donde no se respetaban los derechos humanos, la universidad no podía vivir encerrada como en un claustro colonial, ciega, sorda, muda, insensible a las angustias populares y al grito redentor de las multitudes. Tenía y tiene la ineludible obligación de proyectarse socialmente; asumir un compromiso con el alto valor de la justicia social. De allí la pregunta formulada entonces por Orrego y su correspondiente respuesta: "¿Cómo puede el hombre consagrarse a la ciencia, a las artes y al ejercicio de las disciplinas intelectuales sino no hay libertad? Hay que esforzarse por conquistarla previamente. Hagámonos, primero, países justos para hacernos, luego, países sabios." ${ }^{32}$

Pide a las nuevas generaciones realizar el objetivo más sagrado del hombre: la responsabilidad suprema de crear una nueva vida, esto es, vivir la cultura, realizarse por medio de ella, que le es privativa y sin la cual pierde su condición humana. Y para vivir la cultura es indispensable que la universidad se proyecte al pueblo y que éste se incorpore a la universidad. Sobre esta relación entre universidad y pueblo anota los siguientes términos: "Universidad y pueblo son dos vasos comunicantes cuyo nivel superior o inferior lo determinan la mayor o menor mentalidad y moralidad de ambos. Son si se quiere dos factores intercambiables que presiden todo el proceso histórico". ${ }^{33}$ Estos conceptos fueron escritos en 1928; consecuente con ellos, en 1947, desde su cargo rectoral sostiene que la universidad tiende a satisfacer las justas aspiraciones de los hijos del pueblo porque la universidad es, precisamente, una institución del pueblo. Pero no se queda sólo en palabras, sus ideas las lleva a la acción. Y allí están sus realizaciones como rector que han servido y siguen sirviendo a los hijos del pueblo: organismos académicos y obras materiales.

La más alta misión espiritual que asigna a las universidades, aparte de la no menos alta que debe ejercer en el campo personal, es la de ser depositaria y discernidora de la experiencia histórica de un pueblo, sin la cual es imposible conseguir la consolidación

\footnotetext{
31 Ibídem, p. 308.

32 ORREGO, Antenor. (1968): "Cruzada por la libertad del estudiante," en La Reforma Universitaria, DEL MAZO, Gabriel. Lima, Universidad Nacional Mayor de San Marcos, $3^{\mathrm{a}}$. ed., t 3, p. 111.

33 Ibídem, p. 310.
} 
y la estabilidad de las instituciones políticas. Esto conlleva su idea de una universidad dinámica e integral puesta a tono con la vida contemporánea en todas sus manifestaciones.

Por eso siente satisfacción al constatar que felizmente en el Perú, las generaciones universitarias del movimiento reformista iniciaron el acercamiento de la universidad al pueblo y de éste a la universidad, con el cual por primera vez se crea cultura opuesta al libro frío y a la letra muerta.

Uno de los organismos académicos creado en su condición de rector de la Universidad Nacional de Trujillo, es la Facultad de Educación mediante la fusión de la antigua Facultad de Letras (1901) y de la Sección Pedagógica (1936). Orrego piensa que esta Facultad “(...) debe ser el vivero de la docencia, no sólo de la docencia primaria o secundaria sino de la misma docencia universitaria", y que "(...) habrá de constituir la columna vertebral de nuestra Casa de Estudios, de donde han de salir profesionales capacitados para la enseñanza de sus respectivas especialidades y técnicos en educación (...)". Lugo añade: "Y con el funcionamiento de la Facultad de Educación tiende nuestra Casa de Estudios a formar maestros de todas las ramas del saber humano. Con el tiempo, esta importantísima Facultad será el eje sobre el cual gire la Universidad en pleno, el punto en el cual converjan todos los Institutos, Secciones y Facultades universitarios que deben tender en lo futuro a crear no sólo especialistas e investigadores, sino ante todo maestros que proyecten su saber y su enseñanza hacia el pueblo." ${ }^{.34}$

Dio vida a los Institutos: Psicopedagógico, de Antropología y de Literatura, y los primeros pasos para la Facultad de Medicina. Visionario del campo de la cultura, y sobre todo, de la educación, considera que la universidad no debería ser ajena a la problemática de los otros niveles educativos; entonces, decididamente se propone poner en funcionamiento dos colegios, uno diurno y otro nocturno, a cargo de la universidad, y su intención es la de abarcar todos los peldaños del sistema educativo, desde el hoy denominado inicial. Es muy significativo el pensamiento citado a continuación:

Más aún, y es muy conveniente que se juzgue serenamente, la Universidad se ha impuesto la misión de tomar al niño desde su más tierna infancia y devolverlo a la sociedad y al mundo con la preparación suficiente: ofrece una Escuela de Aplicación para educar al niño desde los cuatro años hasta los diez u once años; dos Colegios de Educación Secundaria gratuitos también para educandos hasta los 16 ó 17, y a partir de entonces en la Universidad con tendencia a la gratuidad en ésta última, de acuerdo con el espiritu del Estatuto Universitario, y formar un profesional o un investigador al servicio de la Humanidad. ${ }^{35}$

\footnotetext{
34 Ibídem, pp. 13-14.

35 En la Memoria del siguiente año ratifica su idea: la Universidad debe cumplir “(...) su función social de extender los beneficios de la enseñaza a toda la población, empezando por el kindergarten para culminar en la educación superior", labor en la cual colaborarán los futuros profesores que se forman en la Facultad de Educación, p. 14.
} 
Desde el punto de vista académico, el colegio creado fue campo propicio para la investigación y la práctica profesional de los alumnos de la Facultad de Educación. Y desde la perspectiva social, a través del colegio, la Universidad se proyectaba hacia la población, especialmente la de menores recursos económicos; así la Universidad, en las palabras de su Rector, tendía “(...) a satisfacer las aspiraciones de los hijos del pueblo porque la Universidad es, y así debe ser, la institución máxima de los hijos del pueblo." ${ }^{36}$

En previsión de concretar sus aspiraciones de extender el servicio educativo, a los peldaños precedentes, en el plan de ejecución de la ciudad universitaria, ideado por Orrego, figuraron las "Escuelas de Aplicación". La aspiración es ahora una realidad concreta.

Es singularmente explícito cuando relaciona la universidad con su concepción latinoamericanista. En efecto, sostiene que: "La Universidad Peruana debe contribuir a la formación de un nuevo tipo de Universidad Indoamericana y clarificar el sentido original de la cultura que está surgiendo en nuestros países en relación con las viejas culturas de Europa y Asia." ${ }^{37}$ Tal Universidad Indoamericana estará llamada a dilucidar el significado del auténtico mensaje que nuestro continente ha comenzado a aportar al mundo en todas las manifestaciones de la cultura; a investigar, debatir y difundir como contenido educativo las experiencias, los anhelos, las ideas, las realizaciones e intuiciones del hombre de esta parte del mundo. Y tan elevada misión institucional deberá realizarla por medio de todas las Facultades y cátedras sin distinción alguna, no únicamente a través de aquellas pertenecientes al campo humanístico, como podría pensarse de modo simplista; en todas las materias es posible indagar, clarificar y definir nuestra realidad.

En consecuencia, para viabilizar la perentoria e histórica misión asignada a la universidad, Orrego pide a cada uno de los docentes sean químicos, médicos, artistas, filósofos, pedagogos, en fin responsables de todas las cátedras- desplegar sus energías creativas desde el punto de vista del contenido educativo y de la metódica para darle al proceso de enseñanza-aprendizaje una orientación acorde con la problemática del pueblo-continente indoamericano, buscando nuestra identidad cultural, lejos del embeleso europeizante y de la tendencia libresca predominante en casi todas las asignaturas como rezago de la educación teórica de viejo cuño.

Para que este organismo académico, dinámico, flexible e integral, se incorpore gradualmente a la vida total del pueblo, busque soluciones a los problemas locales, regionales, nacionales y se ubique en el contexto mundial, es necesario el concurso de todos sus miembros, profesores, alumnos y graduados, imbuidos de la misión integracionista de la nueva universidad.

\footnotetext{
${ }^{36}$ Ibídem, p. 36.

37 Memoria, 1947. Op. Cit, p. 8.
} 


\section{Integración Latinoamericana Educativa y Cultural}

Gracias a su penetrante pupila, Orrego hizo la disección del continente, lugar o crisol de todas las razas y culturas del mundo, donde se dieron cita fraterna y se fundieron recíprocamente. La integración de los pueblos y culturas, que convergieron en América, otorgan sentido cósmico al hombre de nuestro continente. Y este hombre, síntesis de todas las razas y culturas, es el que debe elaborar un mensaje cultural nuevo de honda orientación humanista y ecuménica. La fusión de los elementos culturales autóctonos con los europeos está tomando una nueva dimensión que hará visible en el futuro la nueva expresión cultural de América Latina en un conjunto homogéneo y unitario; cultura que no la lograremos copiando el aporte del pasado, ni tampoco imitando, como los simios, los ademanes ajenos, sino que será el alumbramiento original de nuestro propio ser. Respecto a la copia del pasado, escribe el maestro que el mensaje de América Latina para el mundo será una expresión "hacia el porvenir y hacia delante; obra de creación y no de copia regresiva; tarea epigenética y no de mimetismo automático. El estudio y la comprensión del pasado ha de servir únicamente como alumbramiento del porvenir, como basamento del futuro". Y en relación a la copia foránea dice: "Europa nos ha educado y tiene aún que educarnos, pero, nosotros tenemos la responsabilidad de rebasar sus limitaciones inherentes, alumbrando, clarificando y definiendo nuestra misión histórica y humana. No es por el camino de la imitación simiesca que la cumpliremos, sino por el camino de la diferenciación y de la creación original." 38

No cae, pues, ni en el prurito indigenista ni en el prurito europeizante. Acepta el pensamiento europeo como fuerza alumbradora, no como cartabón. Entonces, la expresión cultural deberá ser producto de nuestra creación. Ratificando sus ideas apunta: "Nuestro pueblo-continente ya no puede repetir la lección escolar que nos venía de Europa, lo suficientemente aderezada como para impedir y paralizar la iniciativa de nuestra propia autonomía mental". ${ }^{39}$ Considera que las aportaciones ajenas sirven solamente como fuerzas catalíticas que provocan, facilitan y despiertan la creación propia. América Latina ha vivido y vive envenenada por el snobismo europeo. Por no haber penetrado hasta su propia alma, su vida ha sido superficial. Continente-Reflejo, ha deformado las imágenes proyectadas de allende los mares. Sus hombres cultos han sido tales por mimetismo libresco, no por asimilación o digestión.

Es decir, nuestra expresión cultural deberá ser original. Y ella ha de partir en forma coherente desde la llamada por él zona vital del continente, aquella zona de fusión y síntesis generada por la colisión cosmogónica de Europa y América. Superados los antagonismos y contradicciones, se habrá de producir un equilibrio articulado y desde esa zona América irá hacia su unidad cultural, hacia su reencuentro, dejando la enajenación y evasión de sí misma acaecidas desde la conquista. La nueva cultura

\footnotetext{
${ }^{38}$ Pueblo-Continente. Op. Cit, pp. 36 - 75, respectivamente.

39 ROBLES ORTIZ, Elmer. (1992): Las ideas educacionales de Antenor Orrego, Trujillo, Universidad Nacional de Trujillo, p. 51.
}

Rhela. Vol. 13. Año 2009, pp. $101-127$ 
asentará sus raíces en el humus de la desintegración, desde allí se impulsarán los gérmenes vitales con los cuales "habrá de lograrse una distinta y más completa integración de la conciencia, del pensamiento y de la acción humana" ${ }^{40}$ Por la fusión de de gérmenes históricos nativos y foráneos, el nuevo hombre del continente producirá un humanismo americano, una cultura distinta a las anteriores.

Consecuentemente, si América Latina, nuestro pueblo-continente, trata de liberarse del dominio económico, político y cultural, y dejar atrás el subdesarrollo y el colonialismo mental; si busca encontrarse a sí misma, definirse en sus características propias, esenciales y permanentes, el corolario resultante nos indica que ello sólo se podrá conseguir mediante el concurso de una educación sustentada sobre la base de una filosofía de la identidad y de la originalidad creativa, estremecedora de las conciencias y alumbradora del camino de redención social.

El correlato lógico de su rebosante humanismo es una educación para la integración de nuestro pueblo-continente, la integración mediante el intelecto. Piensa que si no se combate la ignorancia y la incomprensión de una política de estilo continental, América Latina quedará rezagada en el proceso mundial de agrupación y colaboración de pueblos. Es clara, pues, la tarea de la educación en el proceso integracionista.

\section{CONCLUSIONES}

Aunque su producción de temas educativos no fue sistematizada en una obra orgánica, Antenor Orrego presenta ideas claras y avanzadas al respecto. Sus planteamientos se inscriben en una concepción humanista y liberadora. Siente profundo respeto por el educando, centro y eje del quehacer educativo. Para él, educar no es inculcar y modelar, vale decir, rechaza a la educación como proceso obsesivo de imposición o de infundir rígidamente ideas o comportamientos, fijar con fuerza reglas inflexibles, plagiar o imitar modos de vida, arquetipos o formulaciones deslumbrantes aunque no se ajusten a la realidad en la cual se pretende implantar o reproducir. Todo ello acusa falta de creatividad e intolerancia.

Cuando sostiene que educar es revelar, le asigna al proceso de enseñanzaaprendizaje la cualidad de manifestar lo oculto, lo ignorado, descubrir o inferir indicios o certidumbres de la existencia de lo no percibido y que es positivo para el ser humano. Se trata de abrir un abanico de posibilidades formativas.

Su frase educar es conducir encierra la idea teleológica de guiar u orientar al ser humano al logro de un propósito formativo, implica pasar de una situación a otra, de un estadio inferior a otro superior, en el camino del perfeccionamiento. Tiene sentido prospectivo, mirada hacia el porvenir; alude a una fluencia, a un discurrir permanente en pos de un fin.

\footnotetext{
${ }^{40}$ ORREGO, Antenor. (1966): Hacia un humanismo americano, Lima, Librería-Editorial Juan Mejía Baca, p. 222.
} 
Y su afirmación educar es ennoblecer significa la consubstancialidad de la educación con el mundo de los valores humanos, tema medular en el campo pedagógico, puesto que los valores son privativos del hombre; la formación en valores no es otra cosa que la formación del hombre, su humanización, inseparable de su socialización e inmersión en su exclusiva esfera de la cultura. Este criterio axiológica entraña, pues, la excelencia o la calidad en el desarrollo humano.

Así, la educación es revelación, conducción y ennoblecimiento. Tres términos sencillos que encierran un rico contenido.

Por lo expuesto, el profesor no debe formar a sus alumnos a su capricho, a su gusto personal, a su antojo, imponerles un contenido de aprendizaje, tallarlos como una escultura, producirlos en serie como objetos de una fábrica. Ontológicamente, esto sería un atentado contra el derecho del educando a ser él y no otro. Asimismo sería una negación de las diferencias individuales: cada ser humano es único, inconfundible, irrepetible. Frente al enfoque humanista es incompatible el concepto dictado de curso tan repetido entre docentes y autoridades educativas. Dictar un curso conlleva intolerancia, autoritarismo, arbitrariedad, un criterio dogmático, fijarse fuertemente a una norma, establecer cartabones, envolverse en parámetros, señalar un precepto, cerrar las puertas de la dialogicidad en la clase. A esta idea corresponde el concepto de preceptor, el que imparte una clase, no el que la comparte con sus alumnos; es un criterio unidimensional. Entonces, es función del profesor ayudar al estudiante a descubrir sus potencialidades, facilitarle las estrategias y herramientas mentales para su aprendizaje, orientarle a construir su propio conocimiento y su propia vida, humanizarlo y socializarlo, elevar al máximo sus energías vitales, facilitarle la expresión de sus cualidades de creador de cultura. Lo cual requiere practicar métodos dinámicos. Así el profesor se levantará para alcanzar el nivel de maestro.

Estas ideas de Orrego fueron escritas desde antes de la llegada a nuestras tierras de las corrientes del constructivismo pedagógico y de la escuela humana. Así mismo, su autor es un adelantado de los métodos activos de resolución de problemas. Orrego condena el criterio reduccionista imperante en la estructuración de los contenidos de las asignaturas desligados de la palpitante realidad social y del avance científico. Para él, si la vida es un permanente discurrir, un torrente de fluencia incontenible, no se la enfrentará con recetas o formulaciones rígidas, sino con una mente abierta, con una educación dispuesta para la transformación, para buscar soluciones a una realidad cambiante. La escuela no se guiará por un criterio insular en el acontecer del mundo, sino ella será una institución que pone al estudiante en relación con su entorno social inmediato y mediato, frente a los grandes problemas que afectan a los seres humanos en los órdenes moral, económico, político, jurídico, social, científico y tecnológico.

Exige a los profesores espíritu creativo, superar los criterios simplistas de enfatizar en actividades pasajeras o epidérmicas. Igualmente, formula un fervoroso llamado a los jóvenes a pensar por sí mismos, a ser originales, buscar ruta propia, descubrir, comprender y transformar la realidad, liberar a hombres y pueblos de toda forma de opresión. 
Para ello, el sistema educativo, y en particular la universidad, deberá considerar en sus currículos las vivencias, las ideas, las expectativas, la fe y el aporte de nuestros países en el campo de las ciencias, artes y letras, lo cual conlleva la investigación de nuestra realidad y la definición de la identidad nacional y latinoamericana. Tal la elevada misión de las universidades que deben nacer y desarrollarse en el seno de la problemática de esta parte del mundo. Antes que otros autores y la UNESCO, él habló de una universidad dinámica o proactiva.

\section{FUENTES}

UNIVERSIDAD NACIONAL DE TRUJILLO. Memoria del Sr. Rector Doctor don Antenor Orrego, al iniciarse el año académico de 1948. Trujillo, 1948.

UNIVERSIDAD NACIONAL DE TRUJILLO. Memoria del Sr. Dr. don Antenor Orrego

Ley de Reforma Universitaria No 10555. Lima, 10 de abril de 1946.

ORREGO, Antenor. (1928): “El gran destino de América ¿Qué es América?”, en Amauta. Lima, Año III, No 12, febrero de 1928.

Año III, $N^{\circ} 16$, julio de 1928 .

. (1928): “Cultura universitaria y cultura popular", en Amauta. Lima.

(1957): Pueblo Continente. Ensayos para una interpretación de la América Latina. $2^{\mathrm{a}}$ ed, Buenos Aires, Ediciones Continente.

Villarreal.

. (1965): Discriminaciones. Lima, Universidad Nacional Federico

Juan Mejía Baca.

(1966): Hacia un humanismo americano. Lima, Librería Editorial

. (1968): Cruzada por la libertad del estudiante, en La Reforma

Universitaria. $3^{\text {a }}$ Ed. DEL MAZO, Gabriel, Lima, Universidad Nacional Mayor de San Marcos, $\mathrm{t} 3$.

Razgón.

(1977): El monólogo eterno. $3^{\mathrm{a}}$ Ed. Trujillo, Empresa Editora La

Editores.

(1989): Mi encuentro con César Vallejo. Bogotá, Tercer Mundo

. (1995): Obras completas. Lima, Editorial Pachacutec, 5 ts.

\section{SELECCIÓN BIBLIOGRÁFICA}

ABUTTÁS, Juan y otros. (2009): Antenor Orrego, la unidad continental y los orígenes de la modernidad en el Perú. Lima, Fondo Editorial del Congreso del Perú.

CHANG RODRÍGUEZ, Eugenio. (2004): Antenor Orrego, modernidad y culturas americanas. Páginas escogidas. Lima, Fondo Editorial del Congreso del Perú.

RIVERO AYLLÓN, Teodoro. (2003): Antenor Orrego: meditaciones sobre la universidad, Trujillo, Trilce Editores. 
ROBLES ORTIZ, Elmer. (1992): Las ideas educacionales de Antenor Orrego. Trujillo, Universidad Nacional de Trujillo.

. (1996): Desarrollo histórico de la Facultad de Educación de la Universidad Nacional de Trujillo, Trujillo, Universidad Nacional de Trujillo.

. (2005): "Cultura popular y cultura política: Su relación con la universidad en el pensamiento de Antenor Orrego", en Antenor Orrego. V. 16. Número 2425. Trujillo, enero-diciembre 2005. Revista Oficial de la Universidad Privada Antenor Orrego, pp.135-143.

(2006): "Educación y universidad en el pensamiento de Antenor Orrego", en Acta Médica Orreguiana Hampi Runa. Volumen 6. Número 1. Trujillo, eneroabril 2006. Facultad de Medicina de la Universidad Privada Antenor Orrego.

TÜNNERMANN BERNHEIM, Carlos. (1997): "La educación superior en América Latina y el Caribe en su contexto económico, político y social", en Hacia una nueva educación superior. Actas de la Conferencia Regional Políticas y Estrategias para la Transformación de la Educación Superior en América Latina y el Caribe, realizada en La Habana, del 18 al 22 de noviembre de 1996. Luis YARZÁBAL, Editor. Caracas, CRESALC/UNESCO.

UNESCO. (1995): Documento de política para el cambio y el desarrollo de la educación superior, París, Talleres de la UNESCO.

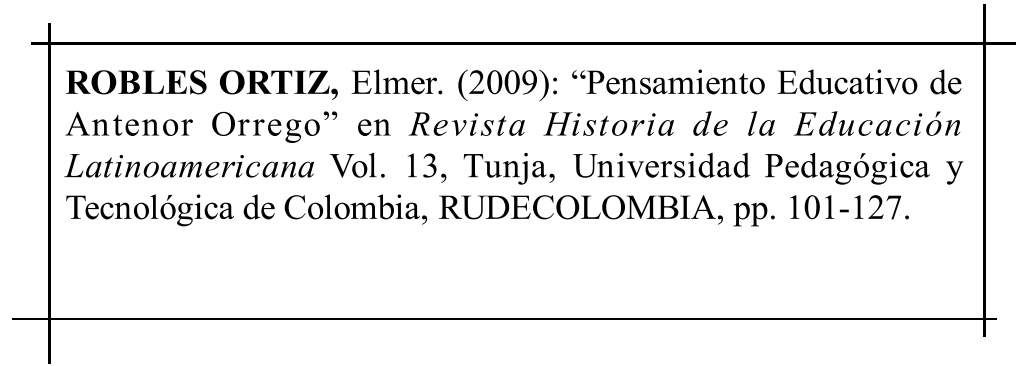

Rhela. Vol. 13. Año 2009, pp. $101-127$ 